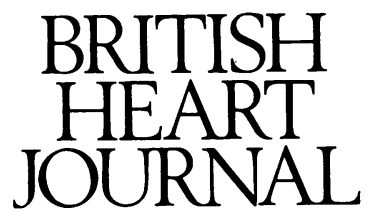

\title{
Editorial
}

\section{Angioplasty of occluded coronary arteries: is it worth the effort?}

The angiographic appearance of a coronary stenosis to a large extent determines the chances of success of percutaneous transluminal coronary angioplasty (PTCA). ${ }^{12}$ An occluded coronary artery poses problems because the morphology of the lesion cannot be fully assessed. Little or no information is available on lesion length and eccentricity and the vessel distal to the site of occlusion may conceal additional stenoses that can prejudice a successful result. With such imperfect information available before the procedure it is not surprising that the reported primary success rates for angioplasty of occluded coronary arteries are not as good as those for angioplasty of stenotic lesions. ${ }^{3-5}$ Nevertheless, there is evidence that angioplasty is being performed on an increasing proportion of occluded coronary arteries. ${ }^{67}$ In the United Kingdom this may be prompted by expanding surgical waiting lists, an increased readiness to perform angiography in patients with recent myocardial infarction, and a reluctance to do bypass surgery on patients with single vessel disease.

The reported primary success varies, but rates approaching $80 \%$ have been reported in selected patients by experienced operators. ${ }^{78}$ However, the average for published reports is around $65 \% .^{9}$ It has been reported that the primary success rate has not improved over the years. ${ }^{9}$ However, it is likely that there has been some improvement because early reports may have falsely inflated the success rates by including functional occlusions. ${ }^{3710}$ It is likely that these represent severe coronary stenoses - in which the primary success rates were similar to the results of angioplasty of subtotal stenoses. ${ }^{3-5}$ More recent reports have concentrated on experience with totally occluded arteries..$^{811-13}$ Despite the definition of occlusion becoming more rigorous, the success rates for angioplasty have remained constant, suggesting a net overall improvement.

Angioplasty of occluded coronary arteries is potentially a more lengthy procedure than conventional PTCA. This is reflected by the practice of using a "stepped" approach to equipment selection. ${ }^{7814}$ Conventional guide wires of increasing stiffness and size are used to cross the occlusion if one fails. While this strategy improves the chances of ultimate success, it is expensive to use two or three wires with assorted probing catheters and balloons.

The use of specially designed equipment has improved the reported primary success rates and reduced procedure time. ${ }^{812}$ In a prospective randomised study the Magnum wire/Magnarail system was better than conventional equipment in PTCA of occluded vessels. ${ }^{13}$ Such systems are more expensive than conventional equipment but they may work out cheaper than the stepped approach. Recent experience with dedicated equipment by experienced operators seems to have improved the primary success rates to about $70 \%-75 \% .{ }^{812} 13$

Occlusion angioplasty has been advocated as "safe" based on the premise that a persistently occluded artery is unlikely to produce clinical deterioration. ${ }^{78}$ However, Ruocco et $a l,{ }^{4}$ reporting the experience of National Heart, Lung and Blood Institute (NHLBI), suggested that the serious complication rate was similar to that of PTCA of subtotal stenoses. The risk of death, infarction, or urgent coronary surgery was $6 \%$ for single vessel and $9 \%$ for multivessel procedures. Others have confirmed that the complication rates are low but not zero. ${ }^{31115}$ Extensive intimal dissection with occlusion of a side branch, ${ }^{12} 1516$ coronary perforation, ${ }^{17}$ and distal embolisation ${ }^{18}$ have all been reported and may cause ischaemia and haemodynamic collapse. The artery may reocclude but collaterals usually prevent $Q$ wave infarction, ${ }^{19}$ though subendocardial infarcts have been reported. ${ }^{3415}$ Abrupt vessel reclosure may therefore remain undetected. ${ }^{20}$ Unlike conventional procedures where failure is usually secondary to abrupt vessel closure, ${ }^{2}$ failure after occlusion angioplasty is normally the result of an inability to cross the lesion and usually produces no adverse sequelae.

A collateralised occluded artery is functionally equivalent to a $90 \%$ stenosis. ${ }^{19}$ Thus the commonest indication for occlusion angioplasty is angina or provokable ischaemia. ${ }^{378}$ Successful recanalisation, however, has been shown to improve left ventricular dysfunction ${ }^{21}$ and thus a proportion (up to $13 \%$ ) have been performed in the hope of reviving hibernating myocardium. ${ }^{311} 22$

Not all occluded arteries are suitable for attempted recanalisation. The presence of an arterial "lead" was shown to be a favourable feature ${ }^{711}$ as was a relatively recent occlusion. ${ }^{41418}$ Tapered, short occlusions consist histologically of loose fibrous tissue ${ }^{23}$ which may allow a guide wire to pass relatively easily. Long, chronically occluded, calcified arteries with a complex network of bridging collaterals are less suitable. Occluded saphenous vein grafts are rarely reopened even when adjuvant thrombolytic therapy is given. ${ }^{24}$ Extensive collateralisation of the index artery has advantages and disadvantages. On one hand, retrograde opacification to the point of the occlusion allows the length of the occluded segment to be assessed and provides information on distal stenoses. ${ }^{72}$ However, it also implies a high distal coronary "wedge" pressure which may impede anterograde flow and favour reocclusion. ${ }^{1026}$ Stone et al, in contrast, reported that neither the duration nor the length of occlusion predicted an unfavourable outcome. ${ }^{7}$ Similarly arterial calcium was not an adverse feature in this series. 
After a successful procedure $63-66 \%$ of patients noted an immediate improvement in symptoms and exercise tolerance. ${ }^{311}$ This is comparable to the NHLBI results of multivessel angioplasty ${ }^{6}$ but is less than with single vessel PTCA of subtotal stenoses. ${ }^{17}$

Long-term efficacy has been measured in terms of angiographic recurrence. ${ }^{527} 28$ and clinical outcome. ${ }^{3411}$ The studies of angiographic recurrence suggested a high recurrence rate. Between $54 \%$ and $77 \%^{520}$ of lesions returned and $12 \%$ to $25 \%$ of them were reocclusions. ${ }^{828}$

The results of long-term clinical studies were generally more encouraging. ${ }^{3411}$ More than $75 \%$ of patients who had a successful procedure had a long-term clinical success (freedom from death, myocardial infarction, or repeat intervention) and around $90 \%$ experienced no or only minor angina. ${ }^{34}$ Coronary surgery was also less likely to be necessary than in the group in which recanalisation failed. ${ }^{1120}$ Angina state and myocardial infarction were similar in both groups, presumably because of the use of surgery in the group with unsuccessful angioplasty. ${ }^{311}$ The reason for the discrepancy is uncertain. Angiographic studies have tended to be smaller or have relied on incomplete angiographic follow up. Thus they may have overestimated recurrence by concentrating on patients with symptoms.

It is perhaps cautionary to consider the NHLBI experience. ${ }^{4}$ Patients who had a successful occlusion angioplasty had higher mortality after two years follow up than patients undergoing subtotal occlusion PTCA. The effect persisted despite correction for left ventricular function. This may be the result of asymptomatic recurrence. Others suggested that an isolated occlusion is not benign. ${ }^{29}$ Thus, though collaterals may prevent acute infarction, the myocardium may be unable to tolerate an additional occlusion in another vascular territory, particularly if this vessel is feeding the collaterals. However, other large scale studies have suggested that mortality in the group as a whole (after both successful and unsuccessful attempts) is low, with $90-96 \%$ alive at four years. $^{311}$ Myocardial infarction as a manifestation of recurrence is, however, rare. ${ }^{28}$

In summary, balloon recanalisation of coronary occlusions should be considered in the same light as other complex interventional procedures. While the initial success rates are not as high as those for "simple" PTCA, a satisfactory outcome can be achieved in most selected patients. This is particularly true if the operator is experienced and prepared either to change apparatus if unsuccessful or to use dedicated equipment from the outset. Patients should be informed that the serious complication rates are comparable to those of other angioplasty procedures though failure is less likely to produce catastrophe.

DW SMYTH DE JEWITT

Cardiac Department Kings' College Hospital London SE5 9RS

1 Ryan TJ, Faxon DP, Gunnar RP, and the ACC/AHA Task Force Guidelines for percutaneous transluminal coronary angioplasty. $\mathcal{f} A m$ Goll Cardiol 1988;12:529-45.

2 Myler RK, Shaw RE, Stertzer SH, et al. Lesion morphology and coronary angioplasty: Current experience and analysis. 7 Am Coll Cardiol 1992; 19:1641-52.

3 Bell MR, Berger PB, Bresnahan JF, Reeder GS, Bailey KR, Holmes DR Jr. Initial and long-term outcome of 354 patients following coronary balloon angioplasty of total coronary artery occlusions. Circulation 1992; 85:1003-11.

4 Ruocco NA Jr, Ring ME, Holubkov R, et al. Results of coronary angioplasty of chronic total occlusions (the National Heart, Lung, and Blood
Institute 1985-1986 Percutaneous Transluminal Angioplasty Registry). Am f Cardiol 1992;69:69-76.

5 Safian RD, McCabe CH, Sipperly ME, McKay RG, Baim DS. Initial success and long-term follow-up of percutaneous transluminal coronary angioplasty in chronic total occlusions versus conventional stenoses. Am 7 Cardiol 1988;61:23G-28G.

6 Detre K, Holubkov R, Kelsey S, et al. Percutaneous transluminal coronary angioplasty in 1985-1986 and 1977-1981: The Heart, Lung and Blood Institute Registry. N Engl f Med 1988;318:265-70

7 Stone GW, Rutherford BD, McConahay DR, Johnson WL Jr, Giorgi LV, Ligon RW, Hartzler GO. Procedural outcome of angioplasty for total coronary artery occlusion: An analysis of 971 lesions in 905 patients. f Am Coll Cardiol 1990;15:849-56.

8 Hamm CW, Kupper W, Kuck KH, Hofmann D, Bleifeld W. Recanalization of chronic, totally occluded coronary arteries by new angioplasty systems. Am f Cardiol 1990;66:1459-63.

9 Meier B. Chronic total occlusion. In: Topol E, ed. A textbook of interventional cardiology. Philadelphia: WB Saunders, 1990:300-26.

10 Dervan JP, Baim DS, Cherniles J, Grossman W. Transluminal angioplasty of occluded coronary arteries: use of a moveable guide wire system. Circulation 1983;68:776-8.

11 Ivanhoe RJ, Weintrobe WS, Douglas JS Jr, et al. Percutaneous transluminal coronary angioplasty of chronic total occlusions: Primary success, restenosis and long-term clinical follow-up. Circulation 1992;85:106-15. J. Magnum wire for balloon recanalization of chronic total coronary occlusions. Am f Cardiol 1989;64:148-54.

13 Pande AK, Meier B, Urban P, et al. Magnum/Magnarail versus conventional systems for recanalization of chronic total occlusions: a ventional systems for recanalization of chronic total

14 La Veau PJ, Remetz MS, Cabin HS, Hennecken JF, McConnell SH, Rosen RE, Cleman MW. Predictors of success in percutaneous transRosen RE, Cleman MW. Predictors of success in percutaneous transluminal coronary

15 Stewart JT, Denne L, Bowker TJ, et al. Percutaneous transluminal coronary angioplasty in chronic total occlusion. $\mathcal{F}$ Am Coll Cardiol 1993;21:1371-6.

16 Plante S, Laarman GJ, de Feyter PJ, et al. Acute complications of percutaneous transluminal coronary angioplasty for total occlusion. Am Heart $\mathcal{f}$ 1991;121:417-26.

17 Meier B. Benign coronary perforation during coronary angioplasty. Br Heart $\mathcal{F} 1985 ; 54: 33-5$.

18 Kerkeiakes DJ, Selmon MR, McAuley BJ, McAuley DB, Sheehan DJ, Simpson JB. Angioplasty in total coronary artery occlusion: Experience in 76 consecutive patients. 7 Am Coll Cardiol 1985;6:526-33.

19 Meier B, Luethy P, Finci L, Steffenino GD, Rutishauser W. Coronary wedge pressure in relation to spontaneously visible and recruitable collaterals. Circulation 1987;75:906-13.

20 Warren RJ, Black AJ, Valentine PA, Manolas EG, Hunt D. Coronary angioplasty for chronic total occlusion reduces the need for subsequent coronary bypass surgery. Am Heart $f$ 1990:120:270-

21 Melchior JP, Doroit PA, Chatelain P, et al. Improvement in left ventricular contraction and relaxation synchronism after recanalization of
chronic total occlusion by angioplasty. $¥ \mathrm{Am}$ Coll Cardiol 1987;9:763-8.

22 Jost S, Nolte CWT, Simon R, Amende I, Gulba DC, Wiese B, Litchen PR. Angioplasty of subacute and chronic total coronary occlusions: success, recurrence rate, and clinical follow-up. Am Heart $\mathcal{f}$ 1991;122: 1509-14.

23 Katsuragawa M, Fujiwara H, Miyamae M, Sasayama S. Histological studies in percutaneous transluminal coronary angioplasty in chronic total occlusion: comparison of tapering and abrupt types of occlusion and short and long occluded segments. $\mathcal{F} \mathrm{Am}$ Coll Cardiol 1993;21: and short

24 DeFeyter PJ, Serrys P, van den Brand M, Meester H, Beatt K, Suryapranata $\mathbf{H}$. Percutaneous transluminal angioplasty of a totally occluded bypass graft: A challenge which should be resisted. $\mathrm{Am} \mathcal{f}$ Cardiol 1989;64:88-90.

25 Grollier G, Commeau P, Foucault JP, Potier JC. Angioplasty of chronic totally occluded coronary arteries: Usefulness of retrograde opacification of the distal part of the occluded vessel via the contralateral coronary artery. Am Heart $\mathcal{f} 1987 ; 114: 1324-8$.

26 Urban P, Meier B, Righetti A, Rutishauser W. Coronary wedge pressure: A predictor of restenosis after coronary balloon angioplasty. $\mathcal{f} \mathrm{Am} \mathrm{Coll}$ Cardiol 1987;10:504-9.

27 DiSciascio G, Vetrovec GW, Cowley MJ, Wolfgang TC. Early and late outcome of percutaneous transluminal coronary angioplasty of subacute and chronic total occlusion. Am Heart f 1986;111:833-9.

28 Ellis SG, Shaw RE, Gershony G, et al. Risk factors, time course and treatment effect for restenosis after successful percutaneous transluminal coronary angioplasty of chronic total occlusion. $\mathrm{Am} \mathcal{7} \mathrm{Cardiol}$ 1989;63:897-901.

29 Van Lierde JV, Piessens J, Glazier J, Vroix M, De Geest H, Willems JL. Long term prognosis of male patients with an isolated chronic occlusion of the left anterior descending coronary artery. Am Heart $\mathcal{F}$ 1991;122: 1542-7. 